\title{
EVALUATION OF SCARABAEUS SACER DERIVED-CHITOSAN, ANTI- CANCER POTENTIALS AND RELATED CHANGES: IN VITRO STUDY
}

\author{
By \\ AMR ABDELKADER ABDEL WAHID ${ }^{1 *}$, MOHAMED MAGED ${ }^{1}$ \\ AND ALY FAHMY MOHAMED ${ }^{2}$
}

Faculty of Biotechnology, October University for Modern Sciences and Arts (MSA), Egypt $^{1}$ and VACSERA, Dokki, Giza ${ }^{2}$

( ${ }^{*}$ Correspondence: Amr.abdelkader@msa.edu.eg)

\section{Abstract}

Lung and colorectal cancer represent a major health problem worldwide. This study evaluated the cytotoxic effect, anti-cancer properties of beetles derived chitosan. The study conducted using lung (A549) and colorectal (HCT-116) cancer cell lines to identify the anti-cancer effect. Cytotoxicity was evaluated by describing and measuring recoding morphological changes. The viability and related $\mathrm{IC}_{\mathbf{5 0}}$ were cell type and concentration dependent. Also, related cell apoptosis was monitored using PI stain where early and late apoptosis of treated A549 cells was significantly elevated than in case of HCT-116 cell line $(\mathrm{P}<0.05)$ than control. In the meantime, the necrotic $\%$ of treated cells didn't perform any changes between the two cell lines but significantly elevated than that of cell control $(\mathrm{P}<0.05)$. Apoptotic profile was examined and showed up regulation of both proapoptotic genes (P53 and Bax) accompanied with down regulation of BCL-2 in both cell lines.

Keywords: Beetles' chitosan, Toxicity, Cell cycle, Apoptosis, Anti-cancer.

\section{Introduction}

Cancer is a leading cause of death in both economically and developing countries (Torre et al, 2015). Logan et al. (2012) reported that Bowel Cancer Screening Programme in England began operating in 2006 with the aim of full roll out across England by December 2009. Subjects aged 60-69 were invited to complete three guaiac faecal occult blood tests (6 windows) every 2 years, aiming to reduce mortality from colorectal cancer by $16 \%$ in those invited for screening. Cancer $(n=1772)$ and higher risk adenomas $(\mathrm{n}=6543)$ were found in $11.6 \%$ \& $43 \%$ of men and $7.8 \%$ \& $29 \%$ of women respectively. $71 \%$ of cancers were 'early' (10\%polyp cancer, 32\%Dukes A, 30\% Dukes B) \& $77 \%$ were left-sided (29\% rectal, $45 \%$ sigmoid) with only $14 \%$ being rightsided compared with expected figures of $67 \%$ \& $24 \%$ for left and right side from UK cancer registration. In Egypt, Veruttipong et al. (2012) reported that colorectal carcinoma was uncommon, but a high proportion of cases occurred before age 40 years and in rectum. They added that analysis of the 1364 cases of colorectal cancer collected at the Gharbia-population-based cancer registry from 1999-2007 revealed the following important findings: First, a relatively high incidence of colorectal cancer in young subjects under age 40 years and significantly low incidence in subjects 40 years and older. Second, high proportion of tumors located in the rectum. Third, a vast majority of tumors (over 97\%) did not have polyps. Fourth, living in an urban area was associated with higher rates of colorectal cancer, with variability in rates across the region. Eser et al. (2018) stated that there were wide variations in colorectal cancer (CRC) incidence across the world. Historically, the highest incidence rates were reported historically in more developed countries; however, increasing trends were seen in developing countries. Galal et al. (2016) in Saudi Arabia reported that factors that might increase risk of colon cancer include: older age. African-American race, a personal history of colorectal cancer or polyps, inflammatory intestinal conditions, inherited syndromes that increase colon cancer risk. They added that family history of colon cancer, low-fiber, high-fat diet, the sedentary lifestyle, diabetes, obesity, smoking, alcohol and radiation therapy for cancer played the major role. Nanavaty et al. 
(2014) in USA reported that lung cancer was the leading cause of cancer death in the United States. Results from the National Lung Screening Trial (NLST) showed that low-dose computed tomography (CT) is capable of detecting lung neoplasms in individuals at high risk. However, whether it is advantageous to perform lung cancer screening on these patients is a significant concern, as are the potential adverse outcomes from screening They concluded that Guidelines should be established to not only help identify an appropriate screening population, but also develop standards for radiological testing Abdel-Rahman (2018) in Egypt reported that in spite of the apparently beneficial role of surgery for some patients with metastatic disease, the absence of adequate information about systemic therapy as well as associated comorbidity hindered the generation of definite conclusions. He concluded that the prospective study was a must to confirm the role of surgery in the setting of metastatic disease. Muxika et al. (2017) reported that chitin is one of the most abundant natural polysaccharides in the world and it is mainly used for the production of chitosan by a deacetylation process. Chitosan is a bioactive polymer with a wide variety of applications due to its functional properties such as antibacterial activity, non-toxicity, ease of modification, and biodegradability. This review summarizes the most common chitosan processing methods and highlights some applications of chitosan in various industrial and biomedical fields. They concluded that environmental concerns of chitosan-based films, considering the stages from raw materials extraction up to the end of life after disposal, are also discussed with the aim of finding more eco-friendly alternatives. Hadwiger and McBride (2006) described a strategy for disease control using lower levels of copper sulfate pentahydrate in combination with a chitosan sticker and complexing agent. They added that the combination provided moderate control of late blight and protection against copper-related leaf yel- lowing at copper levels approximately 40 fold lower than those recommended for a commercial fungicide with copper hydroxide as the active ingredient. Rinaudo (2006) stated that chitin was the second most important natural polymer in the world and, the most important derivative of chitin, outlining the best techniques to characterize it and the main problems encountered in its utilization. They added that chitosan, which is soluble in acidic aqueous media, is used in many applications (food, cosmetics, biomedical and pharmaceutical applications).

This study aimed to evaluate the in-vitro activity of chitosan derived from the Scarab Beetle (Scarabaeus sacer; Scarabaeoidea: Coleoptera) as an anti-cancer agent

\section{Materials and Methods}

All materials of human lung carcinoma were obtained from the American type culture col-lection (ATCC-A549) and colorectal carcinoma (HCT-116) cell lines and Scarabaeus sacer-derived chitosan were kindly supplied by International Center for Advanced Researches. Chitosan was sterilized using ethylene oxide $\left(\mathrm{C}_{2} \mathrm{H}_{4} \mathrm{O}\right)$ at $52^{\circ} \mathrm{C}$ for 6 hrs. Cell lines were maintained according to the standard recommended instructions. Cell culture medium, trypsin and ethylenediaminetetraacetic acid and fetal bovine serum (FBS) were purchased from (GIBCO, USA) and Cell culture flasks were purchased from (TPP, Swiss).

Cytotoxicity assay: Cancer cells were propagated in $75 \mathrm{~cm}^{2}$ cell culture flasks using Roswell Park Memorial Institute medium (RPMI-1640) supplemented with $10 \%$ fetal bovine serum (FBS) and incubated in 5\% $\mathrm{CO}_{2}$ incubator at $37^{\circ} \mathrm{C}$. Confluent cells were detached using $0.25 \%$ trypsin solution and $0.25 \%$ ethylenediaminetetraacetic acid for $5 \mathrm{~min}$. Cells were plated at a concentration $2 \times 10^{5}$ cells $/ \mathrm{ml}$ in $96-$-well cell culture plates and incubated at $37^{\circ} \mathrm{C}$ for $24 \mathrm{hrs}$ to achieve confluence. Medium was decanted and fresh one with twofold serially diluted concentrations of beetles' chitosan was added after being dissolved in $1 \%$ acetic acid for cyto- 
toxicity determination using colorimetric MTT reduction assay. Dead cells were washed out by phosphate-buffered saline (PBS), and $50 \mu \mathrm{l}$ of MTT stock solution $(5 \mathrm{mg} / \mathrm{ml})$. After $4 \mathrm{hrs}$ incubation, the supernatants were discarded and formazan precipitates were solubilized by adding $50 \mu \mathrm{l} /$ well of dimethyl sulfoxide (DMSO). Plates were incubated in dark for $30 \mathrm{~min}$ at $37^{\circ} \mathrm{C}$, and absorbance was determined at a wavelength of $570 \mathrm{~nm}$ by microplate reader (ELX-800, Biotek, USA) after Ciapetti et al. (1993). Cell viability percentage was calculated using the following formula:

Cell viability $\%=\underline{\text { Mean OD of treated wells x } 100}$ Mean OD of control well

Cell viability\% was plotted against chitosan concentrations. $\mathrm{IC}_{50}$ values were determined using Masterplex-2010 Software Program. Beetles' chitosan effect as anticancer synergistic agent was examined by evaluating its' cytotoxic potential in A549 \& HCT-116 cell lines. Cells pretreated with $\mathrm{IC}_{50}$ concentration of chitosan for $24 \mathrm{hrs}$. Morphological alterations of cells were analyzed using an inverted microscope (NikonJapan).

Cell cycle analysis: A549 \& HCT-116 cells pre-cultured in $25 \mathrm{~cm}^{2}$ cell culture flasks were treated with IC50 of chitosan dissolved in RPMI-1640 medium, for $24 \mathrm{~h}$. For analyses, cells were harvested and fixed gently with $70 \%$ ethanol in PBS at $4^{\circ} \mathrm{C}$ overnight and then re-suspended in PBS containing $40 \mu \mathrm{g} / \mathrm{ml} \mathrm{PI}+0.1 \mathrm{mg} / \mathrm{ml}$ RNase $+0.1 \%$ Triton $\mathrm{X}-100$ in a dark room. After $30 \mathrm{~min}$ at $37^{\circ} \mathrm{C}$, cells were analyzed using a flowcytometer (Becton-Dickinson, San Jose, CA, USA) equipped with an argon ion laser at a wavelength of $488 \mathrm{~nm}$. Cell cycle and subG1 group were determined and analyzed, as previously.

mRNA expression levels of cell apoptosisrelated genes: Total RNA was extracted from control and treated A549 \& HCT-116 cells using Gene JET RNA Purification kit (Fermantus, UK) after manufacturer's protocol. Concentration and integrity of the RNA were assessed spectrophotometrically at the 260/280nm ratio and by gel electrophoresis, respectively.

First-strand of cDNA was synthesized with $1 \mu \mathrm{g}$ of total RNA using a Quantitect Reverse Transcription kit (Qiagen, Germany) in accordance with the manufacturer's instructions. The samples were subsequently frozen at $-80^{\circ} \mathrm{C}$ until usage for determination of the expression levels of P53, Bax and Bcl-2 genes using real-time PCR. Quantitative Real-time PCR was performed on a Rotor-Gene Q cycler (Qiagen, Germany) using QuantiTect SYBR Green PCR kits (Qiagen, Germany) and reverse primers for each gene. Nucleic acid sequences of the primers were as follows: P53 (F: 5'-TCA GAT CCT AGC GTC GAG CCC-3' \& R: 5'-GGG TGT GGA ATC AAC CCA CAG-3') and Bax (F: 5'-ATG GAC GGG TCC GGG GAG CA-3' \& R: 5'-CCC AGT TGA AGT TGC CGT CA-3') as well as anti-apoptotic gene Bcl-2 (F: 5'-GTG AAC TGG GGG AGG ATT GT-3' \& R: 5'-GGA GAA ATC AAA CAG AGG CC-3') compared to $\beta$-actin as a housekeeping gene (F: 5'-CAA GGT CAT CCA TGA CAA CTT TG-3' \& R: 5'-GTC CAC CAC CCT GTT GCT GTA G-3'). Real-time PCR mixture consisted of $12.5 \mu \mathrm{L} 2 \mathrm{x}$ SYBR Green PCR Master Mix, $1 \mu \mathrm{L}$ of each primer $(10 \mathrm{pmol} / \mu \mathrm{L}), 2 \mu \mathrm{L}$ cDNA, \& $8.5 \mu \mathrm{L}$ RNase-free water in $25 \mu \mathrm{L}$. Amplification and cycles were done at $95^{\circ} \mathrm{C}$ for $15 \mathrm{~min}$ to initial activation, followed by 40 cycles of denaturation at $94^{\circ} \mathrm{C}$ for $15 \mathrm{~s}$, annealing at $60^{\circ} \mathrm{C}$ for $30 \mathrm{~s}$, and then at $72^{\circ} \mathrm{C}$ for 30 s. Melting curves were performed by Real-time PCR to determine the specific amplification of single products of interest. A standard curve assay was done to determine the amplification efficiency of the primers. Relative fold changes in the expression of target genes (P53, Bax and Bcl-2) were accomplished using comparative $2^{-\Delta \Delta \mathrm{Ct}}$ method with the $\beta$-actin gene as an internal control to normalize the target gene expression level. $\Delta \Delta \mathrm{CT}$ was the difference between the mean $\Delta \mathrm{CT}$ (treated) and mean $\Delta \mathrm{CT}$ (con- 
trol), where $\Delta \mathrm{CT}$ was the difference between the mean CT gene of interest and mean CT internal control gene in each sample. Logarithmic transformation was performed on fold change values before statistical analyzed, using fold change values of three replicates for each gene measurement.

Statistical analysis; Differences between treated and untreated cells was determined using one-way ANOVA. $\mathrm{P}$ values less than 0.05 were considered significant.

\section{Results}

The chitosan induced the cell rounding (A549 \& HCT-116), surface detaching and membrane rupture. Also, the cell viability was concentration and cell type dependent and $\mathrm{IC}_{\mathbf{5 0}}$ as well (Figs. 1, 2). Pro and antiapoptotic genes were estimated post-treatment showed upregulation in P53 and Bax. Down-regulation of $\mathrm{Bcl} 2$ occurred as compared with values in both cell lines (Fig. 3). Cell toxicity was accompanied with cell apoptosis that was cell type dependent with a significant elevated in percentage of early and late apoptosis in A549 cell line compared with apoptosis profile of HCT-116 and untreated A549 \& HCT-115 cell controls. The necrotic \% of treated cells didn't show any change between the two cell lines but compared with its values in cell control showed a significant change (Figs. 4, 5).

\section{Discussion}

Generally speaking, Scarabaeus sacer occurs in coastal dunes and marshes around the Mediterranean Basin, North Africa, southern Europe and parts of Asia mainly Afghanistan, Corsica, Cyprus, Ethiopia, France, Iran, Israel, Italy, Morocco, Sardinia, Sicily, Sudan and Syria. This beetle is almost exclusively a coastal species, living only in dunes and coastal marshes (Remler, 2010). Chitosan is of the most common example derived from crustacean, insects. Chitin derived chitosan proved to be of anticancer potential. The present study showed that chitosan gave a promising effect on cancer cell lines (HCT-116 \& A549) and toxicity was a time and concentration dependent manner.
Grösch et al. (2001) evaluated the involvement of COX-dependent and COX-independent mechanisms further, we assessed the effects of celecoxib (selective COX-2 inhibitor) and SC560 (selective COX-1 inhibitor) on cell survival, cell cycle distribution, and apoptosis in three colon cancer cell lines, which differ in their expression of COX-2. Both drugs induced a G0/G1 phase block and reduced cell survival independent of whether or not the cells expressed COX-2. Celecoxib was more potent than SC560. The G0/G1 block caused by celecoxib could decrease expression of cyclin A, cyclin B1, and cyclin-dependent kinase- 1 and an increased expression of cell cycle inhibitory proteins p21Waf1 and p27Kip1. Celecoxib, but not SC560 induced apoptosis that was also independent of the COX-2 expression of the cells. In vivo, celecoxib and SC560 reduced the proliferation of HCT-15 (COX2 deficient) colon cancer xenografts in nude mice, but both substances had no significant effect on HT-29 tumors, which expressed COX-2 constitutively. They concluded that in vitro and in vivo data showed that the antitumor effects of celecoxib were mediated by COX-2 independent mechanisms and are not restricted to COX-2 over-expressing tumors. Maeda and Kimura (2004) found that low-molecular-weight chitosans or oligochitosan might be useful in preventing tumor growth via the activation of intestinal immune functions. Huang et al. (2004) evaluated the effects of molecular weight and degree of deacetylation on cellular uptake in vitro cytotoxicity of chitosan molecules and nanoparticles.used as nanoparticles. They concluded that Transforming chitosan into nanoparticles modified the mechanism of cellular uptake but did not change the cytotoxicity of the polymer toward A549 cells and that chitosan DD had a greater influence than $\mathrm{Mw}$ on the uptake and cytotoxicity of chitosan nanoparticles. In the present study, beetles derived chitosan against A549 \& HCT-116 cancer cell lines. MTT assay determined the viability and cytotoxic effect 
on cell lines. Rezakhani et al. (2014) determined the in vitro effect of a hydroalcoholic crab shell extract on a breast cancer cell line. They found that cell viability decreased depending on dose and time, was significantly different in groups treated with 400,800, \& $1,000 \mu \mathrm{g} / \mathrm{mL}$ doses compared to control group $(p<0.001)$. Increasing the dose significantly increased apoptosis $(p<0.001)$. NO secretion from MCF7 cells significantly decreased in response to different concentrations of the extract in a dose- \& timedependent manner $(p<0.050)$. They concluded that crab shell extract inhibited the proliferation of MCF7 cells by increasing apoptosis and decreasing NO production.

Salehi et al. (2017) stated that chitosan is a semisynthetic bio-based polysaccharide with promising biological and antitumor properties. But, its possible underlying anticancer mechanisms and molecular interactions remained largely unknown. They found that CS exerted an inhibitory effect on the proliferation of MDA-MB-231, MCF-7 \& T47D breast cancer cells in a dose \& time-dependent manner while being non-toxic to fibroblast L929 normal cells. Exposure of MDAMB-231 cells to CS led to depolarization of the mitochondrial membrane, increase in ROS, DNA oxidation, and $\mathrm{S}$ phase cell cycle arrest. Also, EB/AO staining, Annexin-PI staining, TUNEL assay, and altered expression of caspase 3 in MDA-MB-231 cells all indicated that cancer cells progressively became apoptotic upon CS exposure. S phase arrest in MDA-MB-231 cells showed possible CS-DNA interaction. UV-visible spectroscopy confirmed CS interaction with DNA, and competitive displacement fluorescence assay revealed a binding constant of $7.6 \times 10^{5} \mathrm{M}^{-1}$ for CS. Its binding modes with DNA were established by $\mathrm{CD}$ analysis.

Ghaly et al. (2018) reported that the shrimp (Crustacean) derived chitosan have anti-cancer activity that was assured via induced cell toxicity, cell type and concentrations dependent. Cell cycle, cell arrest profile was accompanied with up \& down regulation of the pro-apoptotic \& anti-apoptotic genes.

\section{Conclusion}

Beetle, Scarabaeus sacer' derived chitosan showed anticancer activity against lung and colorectal cancer cell lines via cytotoxicity that was concentration and cell type dependent. Toxicity proved apoptosis that was monitored via genetic profile assessment, accompanied with high level of early and late apoptosis. The outcome data showed that along with being a safe biopolymer to normal cells, CS can be considered as an effectual anticancer agent.

\section{Acknowledgement}

The work kindly supported by the Faculty of Biotechnology, October University for Modern Sciences and Arts.

The authors would to thanks Dr. Gehan Safwat, Vice Dean, Faculty of Biotechnology, for kindly revised the manuscript.

\section{References}

Abdel-Rahman, O, 2018: Outcomes of surgery as part of the management of metastatic nonsmall-cell lung cancer: A surveillance, epidemiology and end results database analysis. $\underline{\text { Cancer }}$ Invest. 36, 4:238-45

Eser, S, Chang, J, Charalambous, H, Silverman, B, Demetriou, A, 2018: Incidence patterns of colorectal cancers in four countries of the Middle East Cancer Consortium (Cyprus, Jordan, Israel, and İzmir, Turkey) compared with those in the United States surveillance, epidemiology, and end results program. Turk. J. Gastroenterol. 29, 1:36-44.

Ghaly, CAF, Bakaar, A, Mohamed, AF, 2018: In vitro assessment of anticancer activity of shrimp derived chitosan and related apoptotic profile alteration. J. Egypt. Soc. Parasitol. 48, 2: 379-88

Galal, YS, Amin, TT, Alarfaj, AK, Almulhim, AA, Aljughaiman, AA, et al, 2016: Colon Cancer among Older Saudis: Awareness of risk factors \& early signs, and perceived barriers to screening. Asian Pac. J. Canc. Prev. 17, 4:1837-46.

Grösch, S, Tegeder, I, Niederberger, E, Bräutigam, L, Geisslinger, G, 2001: COX-2 independent induction of cell cycle arrest and apoptosis in colon cancer cells by the selective COX-2 inhibitor celecoxib. FASEB J.15, 14:2742-4. Hadwiger, LA, McBride, PO, 2006: Low-level 
copper plus chitosan applications provide protection against late blight of potato. (C) Plant Management Network.

Huang, M, Khor, E, Lim, LY, 2004. Uptake and cytotoxicity of chitosan molecules and nanoparticles: effects of molecular weight and degree of deacetylation. Pharm. Res. 21, 2:344-53.

Logan, RF, Patnick, J, Nickerson, C, Coleman, L, Rutter, MD, et al, 2012: outcomes of the bowel cancer screening programme (BCSP) in England after the first 1 million tests. Gut 61, 10:1439-46

Maeda, Y, Kimura, Y, 2004: Antitumor effects of various low-molecular-weight chitosan's are due to increased natural killer activity of intestinal intraepithelial lymphocytes in sarcoma 180bearing mice. J. Nutr. 134, 4:945-50.

Muxika, A, Etxabide, A, Uranga, J, Guerrero,
P, de la Caba, K, 2017: Chitosan as a bioactive polymer: Processing, properties and applications. Int. J. Biol. Macromol. 105, Pt 2:1358-68. Nanavaty, P, Alvarez, M, Alberts, W, 2014: Lung cancer screening: advantages, controversies, and applications. Canc. Control 21, 1:9-14.

Remler P, 2010: Scarab beetle: Egyptian Mythology A to Z ( $3^{\text {rd }}$ ed.) ISBN 978-1-60413-926-6.

Rezakhani, L, Rashidi, Z, Mirzapur, P, Khazaei, M, 2014: Antiproliferatory effects of cr$\mathrm{ab}$ shell extract on breast cancer cell line (MCF7). J. Breast Canc. 17, 3:219-25.

Salehi, F, Behboudi, H, Kavoosi, G, Ardestani, S, 2017: Chitosan promotes ROS-mediated apoptosis and $\mathrm{S}$ phase cell cycle arrest in triplenegative breast cancer cells: Evidence for intercalative interaction with genomic DNA. RSC Adv. J, 7:431-41

\section{Explanation of figures}

Fig.1: Cell viability after treatment with beetle derived chitosan using MTT Assay relative to concentration Viability of cells decreased by increasing concentration of chitosan, cell viability decreased to $25 \%$ by increasing chitosan concentration $1000 \mu \mathrm{g} / \mathrm{ml}$ in HCT-116 cell lines while reaching $30 \%$ in A549 cell line Fig. 2: $\mathrm{IC}_{50}$ values for A549 \& HCT-116 cell lines in both cells using beetles-derived chitosan.HCT-116 cell line showed lower IC 50 value, but A549 showed a stringer inhibitory effect

Fig. 3: Up-regulation and down regulation of pro and anti-apoptotic genes effected by chitosan. Pro apoptotic significantly up regulated and anti-apoptotic gene down regulated in significant way to control cells, Apoptotic profile of A549 more sensitive to chitosan than HCT-116 cells.

Fig. 4: Cell cycle arrest assay of treated and control A549 \& HCT-116 Cell lines. G2-M phase showed variation between treated and untreated A549cell line, variation in case of HCT-116 not remarkable.

Fig. 5: Apoptotic, necrotic profile \& related changes, A549 cell line; significant early \& late apoptosis than HCT-116. Necrosis without significant changes in cell lines

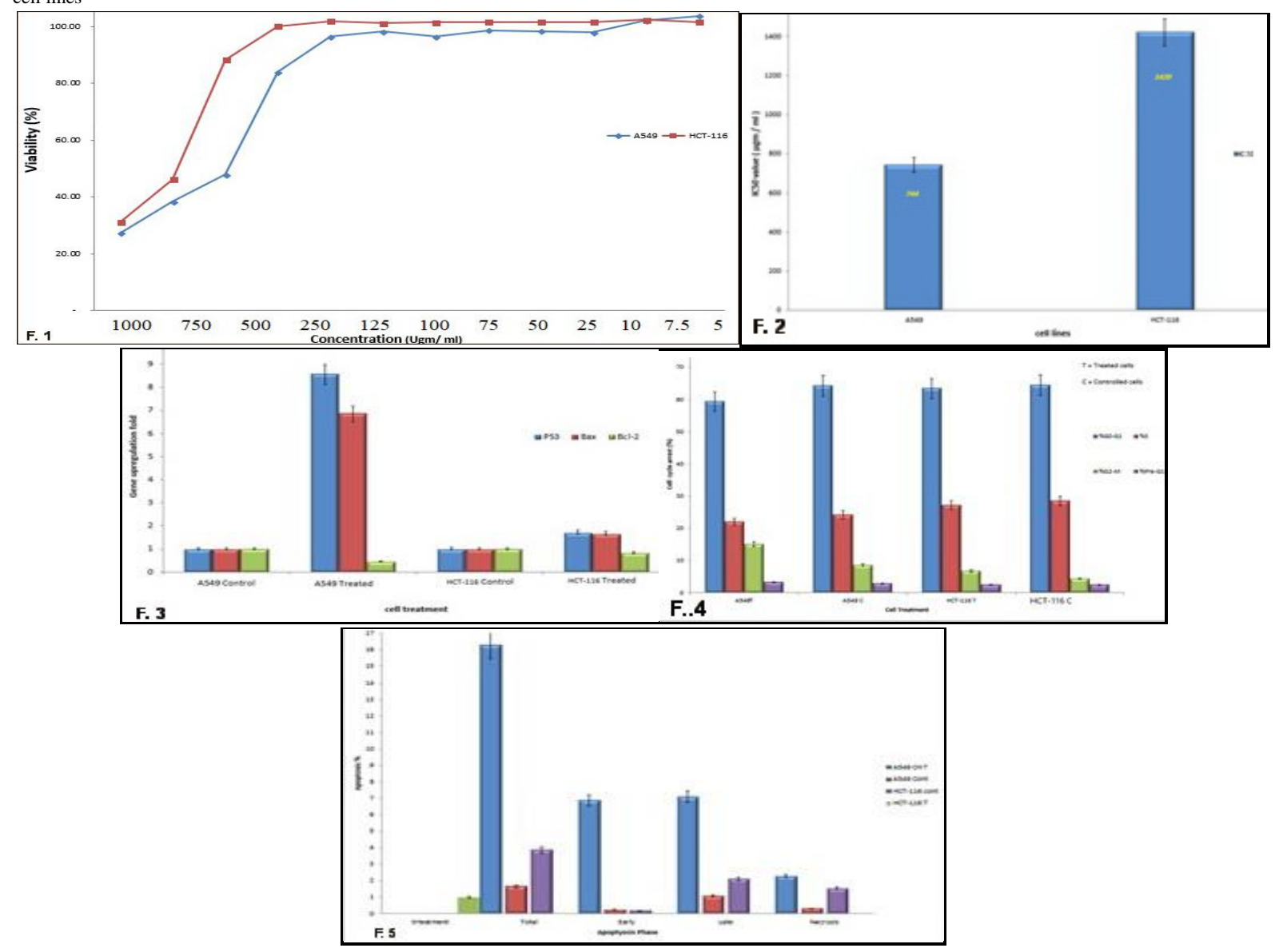

